\title{
Kinship and the State in Tibet and Its Borderlands
}

\section{Introduction}

\author{
Eveline Bingaman \\ PhD Candidate, Institute of Anthropology, National Tsing Hua University, \\ Hsinchu City, Taiwan \\ evelinebingaman@fastmail.com
}

\author{
Heidi E. Fjeld \\ Associate Professor, Department of Community Medicine and Global \\ Health, University of Oslo, Oslo, Norway \\ h.e.fjeld@medisin.uio.no
}

\author{
Nancy Levine \\ Professor, Department of Anthropology, University of California, \\ Los Angeles, CA, USA \\ nelevine@anthro.ucla.edu \\ Jonathan Samuels \\ Associate Faculty Member, Oriental Institute, University of Oxford, \\ Oxford, UK \\ jonathan.samuels@orinst.ox.ac.uk
}

Formations in kinship have received little attention in Tibetan studies, particularly in the period following pivotal publications by Goldstein (1971a; 1971b; 1971c; 1978), Aziz (1978), Levine (1981; 1988), and Diemberger (1993). As additional archives and new field-sites have been made available, studies of Tibet and its borderlands (with borderlands here referring to areas occupied by populations with linguistic, cultural and ethnic affinities with Tibetans) are producing a wealth of data on cultural values and everyday social life, including on kinship and relatedness. The newer studies have addressed and enhanced our understanding of issues raised in the earlier work but have fallen short of bringing these findings to bear on broader and more contemporary concerns within the field of anthropology. Similar observations can be made about historically oriented fields of Tibetan studies, whose 
scholars often address themselves to problems of profound interest to the region but have not made their work accessible to wider audiences. Thus, much of the work in Tibetan studies stands somewhat removed from evolving disciplinary discourses.

This special section aims to explore productive new approaches to the study of Tibet and its eastern borderlands. It brings together four articles that present new material deriving from historically grounded and first-hand field research. The articles focus on how Tibetans imagine their kin relationships and act with reference to them, under conditions of cultural contestation and ongoing social change. Resulting from discussions of two panels at meetings of the International Association of Tibetan Studies (IATS), these articles also work toward opening new lines of inter-disciplinary dialogue.

\section{1 \\ Perspectives from History}

A motivation for compiling this special section has been to encourage more work on the history of kinship and social lives in Tibet. The relative scarcity of historical analyses of family life in Tibetan studies can be attributed, on the one hand, to limited primary sources, both the intimate (personal correspondence and diaries) and the official (registers and legal records), from the pre-twentieth-century era. A second reason is that historians specialising in Tibet have tended to favour the religious and the political as prisms to access its past. Work such as that produced by the ground-breaking project on 'Social history of Tibetan Societies' led by Charles Ramble and Peter Schweiger (see Ramble et al. 2013) are exceptions. But this tendency has generally slowed down the development of a Tibetan social history. Efforts to reconstruct the lived experience of the past are complicated by heavy reliance on historical extrapolation, based primarily on materials from the first half of the twentieth century. Others derive from over-literal reading of Tibetan historical writings, which frequently portray society in an improbably schematic (and invariant) fashion. However, some materials from centuries past, which were authored with the intent neither of presenting a narrative of history nor of documenting social practices, can teach us about the social sphere. To demonstrate, this special section of Inner Asia starts with an article by Jonathan Samuels, in which he explores a previously unreported section of writing composed by the Tibetan 'Prime Minister' Sangye Gyatso (1653-1705) - one of the principal architects of the Tibetan state - devoted to the topic of incest. In this text, Sangye Gyatso describes a threefold classification of incest, supposedly traditional to Tibet, and in a dialogue with an individual named Ngawang considers how aspects of 
it are to be interpreted. The discussion brings questions about marriage restrictions and descent practices, and the role of the state in regulating them, centre stage. Samuels' analysis of the exchange between Sangye Gyatso and Ngawang shows that Tibetan historical writings are in no way devoid of insights about kinship and that when subjected to rigorous interrogation, they have the potential to bring new insights to contemporary discussions.

A linguistic perspective helps bring nuance to the familiar historical picture of Tibetan society as one that should be understood primarily in terms of divisions related to class (nobility, serfs, etc.) and livelihood (agriculturalists, nomads, etc.). Writing in 1361, the Tibetan ruler Ta'i Situ Jangchub Gyaltsen (1302-64) referred to his land as 'a territory with a single Tibetan language' (bod skad rigs gcig pa'i khul). ${ }^{1}$ Despite such assertions, there is a growing appreciation of the complex patchwork of languages spoken in Tibetan regions (e.g. Roche \& Suzuki 2018). Linguistic diversity, especially in the borderlands, has parallels with issues of ethnicity. Although complicated by modern politics, ethnic diversity also has more distant roots. It is the legacy of empire, invasion, settlement, colonisation and migration. The ancestors of the populations of Gyalrong (rGyal rong), for example, were assimilated into Tibet during imperial times. Currently, many of these communities stress their Tibetanness, but they speak non-Tibetan languages (Gyalrongic). As our understanding of language diversity grows, so must our appreciation of the social discourses of these communities. 'Tibetanisation', although a problematic term, has been understood as 'a process of influence, or a process of incorporation' (Roche 2016: 129) and conceived of mainly in terms of the spread of Tibetan language, religion and culture, but it points to the (historical) processes in which socio-cultural worlds meet. Kinship terms and concepts used among Gyalrong-language-speaking communities appear to combine 'classical' Tibetan elements with terms that may be particular to this ethno-linguistic group. Examination of kinship notions and idioms in local communities' relations with 'classical' traditions may also reveal deeper discourses on identity and ethnicity, as well as regional and centre-periphery connections and disconnections.

We suggest that a more targeted approach to historical eras can lead to productive research on kinship and social life in past times. While we are all keenly aware of the impact of the modern state on contemporary Tibetan communities, greater attention to the state can enhance analyses of the more distant past. In Rolf Stein's classic Tibetan Civilization, he describes what he suggests

$1 \quad b K a^{\prime}$ chems mthong ba don ldan, in Byang chub rgyal mtshan (ed. Tshe brtan phun tshogs) 1986. rLangs kyi po ti bse ru rgyas pa. Lhasa: Bod ljongs mi dmangs dpe skrun khang (p. 109). 
is a thirteenth-century definition of a Tibetan family as 'a house, four pillars in size, containing six persons: the married couple (their children, no doubt), manservant and maidservant' (Stein [1962] 1972: 120). Such a definition might appear to be an ideal baseline, the record of a traditional concept: a point of historical orientation from which discussion about regional variations could proceed. But this is not, in fact, of indigenous origin. Nor is it the definition of a 'family', but instead a household. It hails from the census conducted in 1268, during the period of Mongol overlordship of Tibet. This census only defines certain wealthier households, and its interest in them is purely as taxable entities. It provides little information about kinship, or poorer households.

At the same time, this description shows how families and households are closely intertwined with state structures and agencies and must be understood in relation to these. Historically, families and communities are partly defined through the dues and obligations they owe to the state, or stateendorsed religious institutions. In the second article of this special section, Eveline Bingaman gives an example of how tax obligations resulting from ties to the Muli kingdom, a Tibetan Buddhist polity of the Gelugpa school governing southern Kham from the mid seventeenth to the mid twentieth century, impacted household composition and the 'making' of kin in a Naxi community. Taking a historical approach, she explores Muli Monastery's monk levy and the perspectives of Naxi people who were once subject to it. Monk levies (grwa khral or btsun khral) are a form of taxation that ties monastic recruitment to land tenure, a practice that has clear consequences for kinship and marriage practices. Her study reveals that, while largely retaining their linguistic and ethnic distinctiveness despite centuries of close engagement with Tibetans, this Naxi community's encounter with Tibetan authority fundamentally altered kin formation, marriage, inheritance and adoption practices.

Furthermore, we suggest that an approach that targets eras characterised by radical changes could yield interesting historical findings on past social lives. Aside from the imperial era (seventh to ninth centuries), two historical periods stand out: those that respectively mark the beginning of the Mongol era (thirteenth century) and the foundation of the unified Tibetan state (seventeenth century). Both were characterised by territorial expansion, attempts to impose centralised administration and a formalisation of the interface between polity and ethnic minorities, with inevitable impacts on the social domain of all communities. The Mongol-Yuan administration (c. 1270-1354), for instance, created a huge range of titles and property endowments, awarded to those who provided military, religious, or administrative services. Many became hereditary, surviving not only the period in question but many centuries beyond it. This intervention unquestionably shaped concepts of patrilineal inheritance and 
succession, as well as discourses related to prestige and lineage more broadly. It also is no coincidence that the age of the grand genealogy begins here. The two most prominent dynasties were the Sakya (Sa skya), who were appointed by the Mongols, and their eventual opponents and successors, the Phagmodru (Phag mo gru). The most famous genealogy, the 'History of the Lang' (rLangs kyi po ti bse ru rgyas pa), is a genealogical 'account' of the latter dynasty, composed largely to legitimise its rule. The written records of these two dynasties served as models for later genealogical writings and are often cited as evidence of an interest in, and the importance of, genealogies among Tibetans.

There are many challenges when reading historical documents. The dominance of standardised literary vocabulary means that authors are essentially forced to rely on what is often, in terms of the localised phenomena they describe, an outmoded language and set of idioms, related for instance to patrilineality and clans. However, alerted to such idiosyncrasies we may look forward to discovering more of the richer discourses beneath schematisation and in this, a more nuanced understanding of social pasts.

2

\section{Critical Moments in Anthropology and Approaches to the Study of Tibetan Kinship}

Here we consider three of the leading developments and debates in how anthropologists understand kinship and family life in the Tibetan ethnographic region. To select just three arguably limits this discussion to a narrow slice of a rich, broad and ever-changing field. But these particular sets of ideas have served as major inflection points that have made their mark on regional scholarship and have influenced the contributors to this special section. First is the impact of material forces on household and society. Second are changes in the theoretical scaffolding applied to kinship studies - the redirection of attention from principle to process and genealogical universals to culturally specific meanings. The third is a more critical point and focuses on a protracted debate that may be region-specific in its particulars, but parallels debates in anthropology on other regions of the world.

The first major shift arose from emerging concerns with land tenure systems and their impact on class, marriage and family form. The forerunner was Pedro Carrasco's Land and Polity in Tibet (1959). The book was produced at the University of Washington, a pioneering institution in Tibetan studies in the United States and under the influence of Karl Wittfogel, a prominent materialist theorist. It appeared at a time when studies of land tenure were attracting growing attention in anthropology, as evidenced in Edmund Leach's 
polemic but widely read Pul Eliya (1961) and Gananath Obeyesekere's more fully contextualised Land Tenure in Village Ceylon (1967). Land and Polity drew on previously published sources but brought them together to highlight how political authority was based in control over land and describe social divisions and inequality in traditional Tibet. This book was followed by a series of ground-breaking articles by Goldstein (1971a; 1971b; 1971c). These articles illuminated the constraints faced by peasant households, the importance of tax status for various life choices, including polyandrous marriage, and the structure of support for monastic institutions. Analyses of these topics have become a standard in village studies in Tibetan societies - in Central Tibet, Ladakh and the Himalayan borderlands. They are so taken for granted that to include all the publications that reference them would be a task with no end, but these five book-length ethnographies can serve as examples that give pride of place to class, kinship and taxation: Aziz (1978), Levine (1988), Dollfus (1989), Fjeld (2007) and Jahoda (2015). Their dates of publication, which span nearly 40 years, suggest that these are matters of continuing salience for understanding past and present farming communities, a point reiterated in Bingaman's account of monk levies in this special section.

The second set of ideas that changed the studies of kinship in the Tibetan world, as elsewhere, followed the critique associated with the work of American David Schneider (1984). Among the points he made were that anthropologists had naively applied their own Euro-American concepts to other societies and that the anthropological concept of kinship was therefore not cross-culturally applicable. He also suggested that previous analyses depended on a kind of psycho-biological reductionism and that it was a distortion to presume that members of other societies mapped their relationships in genealogical terms. Carsten (2000: $3-5$ ), a leading writer on post-Schneiderian kinship theory, subsequently argued for the reinvention of kinship in 'a postmodern spirit'. She substituted the term 'relatedness' for kinship, as a way of side-stepping layers of theoretical baggage, dodging the analytical opposition between biological and social dimensions of kin relationships and facilitating comparisons between societies that construed kin ties in very different ways.

Work produced in response to this critique came to stress how kin relationships are subjectively construed, situational and processual, while ethnographic descriptions came to highlight what was distinctive about other societies and unlike Eurocentric ideas about procreation and genealogy. These trends were accompanied by a reframing and recontextualising of kinship under the broader and denaturalised rubric of relatedness and the highlighting of culturally diverse ideas about a sense of mutual participation between individuals as the linchpin of kin ties (Carsten 2000; Sahlins 2013). These concerns 
arose in mainstream anthropological theory and have stimulated rethinking about variability and flexibility in the management of marriage and residence across the Tibetan plateau, an argument made by Fjeld in her contribution to this special section. Although there is comparatively little published work on Tibetan kinship after the 200os, we can clearly see a theoretical orientation towards 'relatedness' (see, for example, Craig 2020; da Col 2012a; Langelaar 2017; Wellens 2011). ${ }^{2}$

While the ideas described above are widely accepted, the final issue to be discussed has been the focus of protracted debate and relates to the more recent focus on the house, deriving from Lévi-Strauss's later writings (1982: 174). The question here is how to interpret and convey the significance of social units above the level of the household that serve as an important community resource for collective action. These groups are often described by interlocutors as deriving from historical kin relations, even as the importance of tracing those connections is minimised, presenting researchers with the dilemma of deciding whether genealogical ancestry or the historical relationship between their houses merits greater emphasis. It is worth noting that relationships based on clanship and descent were foregrounded in social evolutionary, Boasian and British structural theory, while the focus on the house is more recent. It also is worth noting that Lévi-Strauss's model is more suggestive than programmatic, but has been productive in conceptualising social relationships in societies characterised by bilateral kinship, as in Southeast Asia. Carsten and Hugh-Jones (1995: 8) describe these so-called house societies as intermediate between elementary, kinship-based societies and modern, class societies and as encompassing the seemingly polar categories of descent and alliance, exogamy and endogamy. Such characterisations also seem to fit many traditional Tibetan farming communities, where households have continuity over generations, with various marriage and inheritance practices contributing to this continuity.

2 This thematic orientation is, however, evident in papers delivered at the last three meetings of the IATS conferences. In Vancouver 2013, the panel, 'The state of Tibetan anthropology: Old predicaments, new directions', convened by Giovanni da Col and Charlene Makley, included papers on new paradigms of kinship. In Bergen 2016, the panel 'Kinship, social organization and history in Tibet and its borderlands: Towards new engagements with anthropological theory,' convened by Wang Tingyu, Jonathan Samuels and Reinier Langelaar, aimed to open new research trajectories beyond descent. The panel in Paris 2019, 'Kinship by choice and friendship by preference: Intimacy and interaction in the Sino-Tibetan borderland', convened by Eveline Bingaman and Wang Tingyu, brought together papers on siblingship, ritual siblingship, lovers and friendship on Tibet's eastern borderland. 
In many ethnographically Tibetan areas, households form or formed associations providing mutual aid, known by different names. In the Nyinba region of northwest Nepal (Levine 1988), they are known as trongbad. In Buddhist Ladakh, they are known as pha spun. ${ }^{3}$ In all of these areas, as far as we know, their mutual obligations are explained in terms of former unity: an ancestral house that devolved into multiple households following occasional partitions between brothers. Ladakhi specialists have debated how to classify pha spun. The debate has focused on whether the relationship is understood in terms of such common ancestry or house affiliations, or in some sense both, given that the households so affiliated consist of individuals who descend, in a genealogical sense, from a particular male ancestor. Some suggest that these groups are based on residence and best understood as a component of a house society, while others argue that they are based on patrilineal descent, and still others describe them as representing something transitional between the two systems, as, for example, clans in the process of dissolution. While Srinivas (1994) described pha spun among Buddhist Ladakhis as fictive kin groups linked by ritual exchanges, Mills (2000) argued that pha spun are based on house membership and that their function is mainly ritual. Kaplanian (2008) took an opposing view, arguing that pha spun are linked by common descent and hence that the construct of house society does not apply to Ladakh. At the same time, Jahoda (2015: 176-8) pointed out that older publications equate these groups with clans and that the significance of kinship and clanship politically and economically has waned over time. All of these interpretations have been advanced with sound evidence and reasoned arguments. If scholars cannot agree, one has to ask whether the problem lies in the accuracy of the ethnographic data with which they are dealing, regional variations, the analytical categories they are using, or with the way anthropologists construct and employ those categories.

We can see similar dynamics in the discussions about tsho ba in Amdo. In Clarke's accounts of eastern Tibetan pastoralists, he writes of nested territorial segments organised around a dominant lineage and states that kinship (including marriage) and territory produce related orders, as kinship relations express themselves in territorial segments and territorial contiguity leads to

3 This is seemingly identical to the similarly named phaipun of far-off Chamdo (L. Gelek, pers. comm. 20o8). In Tsang, pha spun is a generic term that denotes all patrilateral kin, independent of house membership, that do not hold mutual assistance obligations towards each other: see Fjeld, this special section. The term pha spun itself has great antiquity. It appears in Tibetan manuscripts found in Dunhuang (Róna-Tas 1955: 257-8), although the categories of persons to whom the term referred is not entirely clear, as Levine discusses in her contribution to this special section. 
marriages. This makes for an ambiguity between the two principles locally' (Clarke 1992: 398-9). There is no doubt that the very effort of pinning down 'principles' in order to elicit a deeper and consistent generative structure and fitting cases into categories can contribute to ambiguities and ethnographic puzzles. Clarke's ruminations are part of the recent explorations of the category of tsho $b a$ and its possible referents, as seen in Langelaar's historical and contemporary work $(2017 ; 2019)$, and bears similarities to debates on the pha spun in Ladakh. In everyday life, the mixing of idioms of descent and house membership are hardly surprising from the perspective of individual interlocutors.

Theoretical developments in anthropology and its associated disciplines have the potential to bring renewed interest to topics that have been underresearched and open new questions and investigations beyond the protracted debates about which generalised models to apply to Tibetan communities. While the debate concerning the 'house society' is less fruitful, 'the house' as an analytic can serve to open new trajectories of kinship studies in Tibet and its borderlands. Hsu (1998), in a chapter on the social and material life among Naxi and Moso, listed three aspects of what seeing the house as a heuristic device for kinship studies might entail: firstly, an increased emphasis on residence and territory; second, a stronger focus on local concepts of house, hearth and home, which includes not only the locality but also the physicality of the house; and third, a perspective prioritising domestic life as an entry into kinship issues (Hsu 1998: 70-72). These points apply to Tibetan kinship studies as well. Firstly, notions of shared homeland are often seen in skyid sdug associations, which are important networks of mutual aid among Tibetans, inside and outside Tibet (Craig 2020; Fjeld 2008; Swank 2014). Together with other mutual aid networks, such as dga' nye among farmers and gnas tshang among nomads and traders, these are key forms of relatedness that take on new meanings as people change livelihood, move, resettle and renegotiate obligations and expectations. Such moral networks remain to be explored in more detail. Secondly, including the physical house in the analyses of Tibetan households can enrich our understanding of vernacular architecture, connecting relatedness with cosmological and ritual aspects of domestic life. In many Tibetan communities, the house is a meaningful, ritually efficacious space enabling (controlled) human-non-human relations - domestic multispecies relations that it would be exciting to explore in more depth (da Col 2012b; Fjeld \& Lindskog 2017; see also White \& Fijn 2020). Lastly, and connected, approaching kinship through observation of everyday domestic life brings new insight into relatedness formed and enacted by individuals in the periphery of dominant kinship ideologies, and captures the creativity that people 
bring to the production of close relationships and the performative aspects of kin-making and maintaining. More studies on Tibetan relatedness, on siblingship and friendship and lovers, on the relations between classmates, neighbours and new forms of families, as well as networks of assistance and care, and extended socialities among humans and non-humans, have the potential to bring Tibetan ethnography to the centre of social theory debates, also outside regional studies.

\section{Pragmatic, Flexible Kinship and the State}

Another intention of this special section is to put forth the idea of pragmatism and flexibility as a unifying principle of kinship. Early studies that formed the 'classic canon' of Tibetan kinship were conducted within paradigmatic frameworks that lent themselves to static interpretations of kinship itself, its nature and its purpose. In this special section's third article, Nancy Levine begins by interrogating the vocabularies utilised in early accounts of social organisation among Tibetan pastoralists, showing that these introduced conceptual categories that continue to inform ethnography even as their validity becomes increasingly questionable. Levine then addresses the ways in which eastern Tibetan pastoralists are relying on siblings for mutual assistance to manage better the challenges imposed by successive government reforms and rapid economic changes. She argues that everyday kinship practices, which highlight the pragmatic practicalities of kin relations, were overlooked in the earlier anthropological rush to elucidate principles of social life, and in the privileging of relationships based on clan identities and tribal organisation, to the relative neglect of the critical economic and social roles of women in pastoralist societies.

The ways in which kinship is formed, maintained, negotiated and redefined vary to a great extent across the vast and diverse Tibetan ethnographic region. In some areas, house membership is constitutive of individuals' rights and duties, while in other places patrilineal descent groups have organisational effects. Yet, we argue, shared idioms, vernaculars, sensibilities, solutions and adaptations run like a river through this variation. Perhaps one way to think about similarity and difference in social organisation is through a linguistic analogy. Literary, specifically 'classical' Tibetan is a conservative language. It projects homogeneity, uses a standardised vocabulary and does not acknowledge vernacular variations. Spoken Tibetan, conversely, comprises a vast array of diverse dialects (many of which are not mutually intelligible): in each case, 
their relationship with literary Tibetan is different. We may similarly talk of a 'classical' set of kinship principles and practices commonly associated with Tibetan socio-cultural worlds. Different communities may all reference or even claim to maintain 'classical' elements, but their usage of these elements and the way they are expressed and assembled in each setting differ. This great variation - the broad range of possible ways to make connections, ties and alliances, and the common deviances between ideology and practice - perhaps complicates the ambition to produce historically informed kinship studies.

As outlined in full by Heidi Fjeld in the final article of this special section, an approach that takes pragmatism and flexibility as kinship's defining feature has the potential to bring coherence to the broad diversity of kinship practices found across Tibet and its borderlands. Taking the increase of fraternal polyandry in rural Tsang from the 1980 os as a starting point, Fjeld critically examines the notions of descent and lineage and suggests that the analytic frame of houses as moral persons can better explain these changes in marriage practices and preferences, at that particular place and time. This increase, she argues, is an example, not of a house society, but of the pragmatic ways in which marriage - and kinship more broadly - comes to be formed in dynamic interaction with external and internal factors. The inherent flexibility of marriage and kinship is shared across the Tibetan ethnographic region, forming what Fjeld calls a kinship of potentiality.

Each of the contributions in this special section highlights kinship's variability and adaptability in one way or another. In Samuels' article, the crux of the questions Ngawang posed to Sangye Gyatso was how to understand local kinship practices that diverged from the 'orthodox', to which Sangye Gyatso responded that the two (religious thought and secular everyday practice) are of separate ontological domains. Levine's discussion of mutual aid between siblings highlights how inherent pragmatic flexibility supports the emergence of new family forms in the face of changing economic circumstances. Fjeld's discussion of marriage highlights how co-existing marital options offer communities an array of avenues to attend to the specific challenges and opportunities presented at a particular place and time. Bingaman's exploration of Eagleback Naxi's use of adoption and marriage to evade monk levies likewise underscores kinship's potential as an adaptive platform for communities to respond to external as well as internal pressures.

The broad and heterogeneous range of cultural and social possibilities available and the flexibility with which they can be employed to form close relations, networks of assistance and senses of belonging brings connectedness and a degree of unity across the Tibetan ethnographic region. People use 
similar idioms, such as flesh and bone; they consider overlapping principles (such as economic diversity, keeping the family together and fulfilling village obligations) and take similar trajectories when trying to secure a good, or a better, life. They may place varied amounts of emphasis on residence or descent, and they consider monogamy, polyandry or polygyny, neolocal, patrilocal or matrilocal post-nuptial residence, or combinations of these alternatives. Inheritance is similarly open to different possibilities, prioritising sons or daughters, depending on the circumstances they face. People make choices, negotiate and adapt to the economic and political environments they inhabit; they mobilise the human resources accordingly, as described in the articles by Bingaman, Levine and Fjeld. We know that organisational principles do not necessarily lead to practice, as Samuels shows in the case of the seven generations incest taboo, hence the importance of studies of everyday life. Kinship making and maintenance are processes-in-flux, formed in a continuum of potential principles and practices that can be foregrounded or backgrounded in different localities and at different times, in ways that both respond to and shape external and internal factors, concerns and forces.

We find that this pragmatism and flexibility is made clearly visible in interactions between kinship and the state. Hence, exploring the various ways that the state forms and is formed by kinship processes is a potentially productive approach to studies of relatedness in Tibet and its borderlands. States in their very nature are intimately involved and invested in kinship in specific ways, engaging to various degrees in the lives of the individuals, families and communities they govern. While there are undoubtedly important distinctions to account for in the methods, techniques and technologies utilised by democratic versus authoritarian states, a closer look shows that all states are deeply involved in shaping families in intimate ways.

Lambek argues that it 'is a fact of modernity that kinship is partially encapsulated in and by the state'. Modern states, he continues, are constituted by the very making of citizens, by providing birth and death certificates, claiming taxes, registering land ownership across generations and 'producing and authorising the means by which people are related to one another as parents, offspring, siblings, spouses and the like' (Lambek 2013: 257). Implied in Lambek's discussion is the idea that with secularism - a characteristic of what he calls the modern state - the authorisation of kinship production is moved from the domestic and ritual domains (life-cycle rituals, for instance) to being encapsulated by the state. This distinction is not, however, clear-cut in Tibet. Beginning in the seventeenth century, the notion of the chos srid zung 'brel [the union between religion and state] was cited as a ruling principle of the 
Tibetan state headed by successive Dalai Lamas, but religion was separated from the social domain in many distinct ways. As Samuels shows, Desi Sangye Gyatso approached the regulation of marriage and eligible sexual unions with caution. This analysis of Sangye Gyatso's text not only adds complexity to the much-heard concern about kin marriage in Central Tibet, but also draws attention to the relative distance that the (religious) state seems to have maintained from the issues of sexual union, childbirth and marriage. In the text, we see no signs of direct intervention, and even, in Sangye Gyatso's case, a degree of respect for pre-existing customs. Yet, as mentioned above, Ganden Podrang taxation policies had a strong impact on its citizens and the organisation of farming and pastoral communities. Similarly, as part of Tibetan Buddhist polities from imperial to present times, people's lives in the frontier areas have been formed by relation to these states, not only in terms of religious practices, but also directly through tax obligations, as Bingaman's article describes. However, while the Ganden Podrang, and other Tibetan Buddhist polities, it could be argued, 'made' citizens directly through taxation, these states did not to any notable extent seek to 'produce or authorise', in Lambek's words, 'the means by which people are related to one another' (2013: 257).

Moving beyond the distinction between pre-modern and modern states, we suggest a framework that adapts the concept of 'steering' to anthropological and historical explorations of kinship and the state across the Tibet ethnographic region. In sociology and political science, (more recent) political steering theory offers an actor-centric approach to explore the ways a multitude of both government and non-government participants contribute to directing social behaviour towards particular goals (Alpermann \& Zhan 2019; Peters 2007). We do not take the concept of 'steering' to imply a causal relationship between state action and social results, but rather as processes resonating with biopolitics more broadly. We see steering to be assemblages of practices, ideas, and sensibilities, rules and regulations, and elements that somehow move action in certain directions. Indeed, at all levels, there are gaps between persuasion/compulsion and acceptance/compliance - attempts to steer are often inconsistent with or contradictory to the ends they are intended to achieve. Efforts at steering may also be just as liable to produce undesired results as desired ones, and unintended consequences are thus as much a part of the story as acceptance and complicity.

For analytical purposes, the better to compare the ways that states shape kinship in Tibet and its borderlands, we propose a tripartite distinction between modes of steering that are either soft, medium, or hard. Soft steering primarily takes place in the promotion and reinforcement of certain ideas 
and sensibilities about the family and thus is ideological and moral in nature. Medium steering can be observed within the sphere of 'everyday politics' in the ways that state-society interactions are mediated through the social, political, economic and legal systems that act as the frameworks of governance. Finally, hard steering describes the authoritarian mode of state-society interaction, involving the deployment of that part of the state's apparatus dealing with punitive measures.

All four articles in this special section engage with the state, although in different forms, from the Ganden Podrang to local Tibetan Buddhist polities, to the People's Republic of China. Samuels' article, examining Sangye Gyatso's writings on incest, provides an example of the assorted complexities involved in soft steering. As a central figure in the establishment in what was to become the modern Tibetan state, Sangye Gyatso's views on what aspects of social life fell within the purview of the state, and what lay outside it, played a role in the way that state institutions came to be developed. Samuels' exposition of the exchange between Sangye Gyatso and his interlocutor Ngawang reveals that both authors were conscious that Sangye Gyatso's interpretations of different forms of incest and the roles that they play in delineating marriageability had the potential to be read as either a validation or condemnation of actual lived social practice. Sangye Gyatso attempted to handle the matter carefully, so as to avoid alienating certain populations.

In Levine's article, successive changes in the instruments of medium and hard steering, particularly issues surrounding rights to property, provide the background to discussions of practical kinship, the emergence of new family forms and the importance of sibling ties. Pastoralist societies have transited from pre-modern conditions of common property to collectivisation at midcentury, to the late twentieth-century allocation of state-issued, long-term contracts to fixed and bounded parcels, which restrict the commercialisation, exchange and division of land. They have also faced the broader contexts of urbanisation, emerging economic opportunities and compulsory schooling for their children. All of these changes have presented families with new problems that kinship plays an important role in managing.

Changing marriage practices and domestic organisation in Panam in the wake of decollectivisation in Fjeld's article is an example of how political, legal and economic frameworks come together as medium forms of steering and create environments where certain kinship potentialities offer distinct advantages over others. While there is no difficulty in finding examples of hard steering in citizen-state relations in Tibet, registration and regulation of marriages was not prioritised in the 200os, the period described, and, despite being 
prohibited by law, fraternal polyandry was not sanctioned by the state. Fjeld and Levine's articles both present cases of diverging steering efforts, namely, the national decollectivisation of land, which created unintended results. Since its inception, the PRC has attempted to reorganise Chinese society by altering the social and economic foundations of families, reflecting new forms of biopower into the state project (Yeh 2013). For instance, conscious efforts were made to reorganise governance structures in a way that would undermine the authority of lineage elders and would place authority in the hands of monogamously married couples. It was these couples that represented the image of familial modernity that the Chinese state wanted to promote (Yan 2003). Yet, as decollectivisation introduced a new framework of property ownership, which granted hereditary rights to land for all segments of Panam's population, fraternal polyandry's pre-existing normativity began to expand in a way that other frameworks of steering, like marriage laws, were unable to control.

Finally, in addition to exploring soft steering as present in state-led pushes towards monasticism in Tibetan Buddhist polities, and the medium steering mechanisms found in the way that taxation, property ownership and inheritance were organised in the Muli kingdom, Bingaman's article on Muli Monastery's monk levy describes an example of hard steering through the potential use of force. However, the Eagleback Naxi community's response to these measures also shows that adding the threat of punitive action to enforce particular forms of behaviour does not guarantee the success of steering efforts. When confronted with a monk levy policy that only allowed families to keep their eldest- and youngest-born sons in the household, the families found ways to evade the levy, exploiting loopholes in the system by adopting or marrying out sons marked for the levy to other households in the community.

\section{Conclusion}

'The specific quality of kinship', Sahlins writes (2013: iv), 'is "mutuality of being": kinfolk are persons who participate intrinsically in each other's existence; they are members of one another'. Kinship, as close relationship, as relatedness, comes into being, is made and maintained through both the everyday and extraordinary practices, in well-established lines of connectedness and through particularistic ad hoc decisions. These connections and decisions conjoin ideas that anthropologists are conditioned to link to different spheres of social life. When individual men or women seek to compose a work team 
to help with the harvest, to assist when travelling, or to be allies in political conflicts, they look to those who are tied to them in any number of ways. Ties come through their parents, through their membership in collectives, through household linkages, through neighbours, classmates or others. When asked to explain such decisions, they may point to any and all facets of the relationship. Traditionally, anthropologists then attempt to formalise such decisions and to abstract out their supposed essential features - to re-conceptualise them in terms of core principles of descent, territory, or the house as a corporate unit. Nowadays, the discipline has turned away from totalising categories and toward such seemingly unsystematic concepts as assemblages and rhizomes that follow the material semiotic complexity of social life. But anthropologists still try to generalise about and identify regular patterns in the flux of social life. The inherent problem of classification is, of course, that once a pattern is identified, it creates a precedent and may cloud efforts to see social life in other terms, and as such might obscure as much as clarify. Presenting these four articles together, we aim to inspire more explorative approaches that engage with the complexities of kinship relationships in Tibet and its borderlands. Moreover, we hope that greater attention is drawn to potentials: that is, not only the innate potential that the unusually broad range of permissible practices and ways of understanding relatedness among the communities involved seem to offer, but also the potential for greater inter-disciplinary dialogue, particularly between anthropologists and those in the historically orientated branches of Tibetan studies.

\section{Note}

All authors contributed equally to the work. Author names are in alphabetical order.

\section{References}

Alpermann, B. \& S. Zhan. 2019. Population planning after the one-child policy: shifting modes of political steering in China. Journal of Contemporary China 28(117):348-66. Aziz, B.N. 1978. Tibetan Frontier Families: Reflections of three generations from D'ing-ri. New Delhi: Vikas.

Carrasco, P. 1959. Land and Polity in Tibet. Seattle (WA): University of Washington Press. Carsten, J. 200o. Cultures of Relatedness: New approaches to the study of kinship. Cambridge: Cambridge University Press. 
Carsten, J. \& S. Hugh-Jones. 1995. Introduction, in J. Carsten and S. Hugh-Jones (eds), About the House: Lévi-Strauss and beyond: 1-46. Cambridge: Cambridge University Press.

Clarke, G. 1992. Aspects of the social organisation of Tibetan pastoral communities, in S. Ihara \& Z. Yamaguchi (eds), Tibetan Studies: 393-411. (PIATS V, Vol. 2.) Narita: Naritasan Shinshoji.

Craig, S.R. 2020. The Ends of Kinship: Connecting Himalayan lives between Nepal and New York. Seattle (WA): University of Washington Press.

da Col, G. 2012a. The poisoner and the parasite: cosmoeconomics, fear, and hospitality among Dechen Tibetans. Journal of the Royal Anthropological Institute 18(1): 175-95.

da Col, G. 2012b. The elementary economies of Dechenwa life: fortune, vitality, and the mountain in Sino-Tibetan borderlands. Social Analysis 56(1): 74-98.

Diemberger, H. 1993. Blood, sperm, soul and the mountain: gender relations, kinship and cosmovision among the Khumbo (N.E. Nepal), in T. del Valle (ed.), Gendered Anthropology: 88-127. London: Routledge.

Dollfus, P. 1989. Lieu de Neige et de Genévriers: Organisation Sociale et Religieuse des Communautés Bouddhistes du Ladakh. Paris: Éditions du CNRs.

Fjeld, H. 2007. The Rise of the Polyandrous House: Marriage, Kinship and Social Mobility in Rural Tsang, Tibet. PhD dissertation, University of Oslo.

Fjeld, H. 2008. Pollution and social networks in contemporary Tibet, in R. Barnett \& R. Schwartz (eds), Modernity in Tibet: 113-38. (PIATS x.) Leiden: Brill.

Fjeld, H. \& B.V. Lindskog. 2017. Connectedness through separation: human-nonhuman relations in Tibet and Mongolia, in J.H. Remme \& K. Silander (eds), Human Nature and Social Life: Perspectives on extended sociality: 68-82. Cambridge: Cambridge University Press.

Goldstein, M.C. 1971a. Stratification, polyandry, and family structure in central Tibet. Southwestern Journal of Anthropology 27(1): 64-74.

Goldstein, M.C. 1971b. Taxation and the structure of a Tibetan village. Central Asiatic Journal 15(1): 1-27.

Goldstein, M.C. 1971c. Serfdom and mobility: an examination of the institution of 'Human lease' in Tibetan Society. Journal of Asian Studies 30(3): 521-34.

Goldstein, M.C. 1978. Adjudication and partition in the Tibetan stem family, in D.C. Buxbaum (ed.), Chinese Family Law and Social Change in Historical and Comparative Perspective: 205-14. Seattle (WA): University of Washington Press.

Hsu, E. 1998. Moso and Naxi: the house, in M. Oppitz \& E. Hsu (eds), Naxi and Moso Ethnography: Kin, rites, pictographs: 67-99. Zürich: Völkerkundemuseum.

Jahoda, C. 2015. Socio-Economic Organisation in a Border Area of Tibetan Culture. Tabo, Spiti Valley, Himachal Pradesh, India. Vienna: Austrian Academy of Sciences Press. bKa' chems mthong ba don ldan, in Byang chub rgyal mtshan (ed. Tshe brtan phun tshogs) 1986. rLangs kyi po ti bse ru rgyas pa. Lhasa: Bod ljongs mi dmangs dpe skrun khang. 
Kaplanian, P. 2008. Groupes d'unifiliation, parenté et société à maison au Ladakh (Le Phaspun), in M. van Beek \& F. Pirie (eds), Modern Ladakh: Anthropological perspectives on continuity and change: 197-227. Leiden: Brill.

Lambek, M. 2013. Kinship, modernity and the immodern, in S. McKinnon \& F. Fenneli (eds), Vital Relations. Modernity and the persistent life of kinship: 252-71. Santa Fe (NM): SAR Press.

Langelaar, R.J. 2017. Descent and houses in Reb-gong: group formation and rules of recruitment among eastern Tibetan tsho-ba. Archiv Orientalni Special vol. 10: 155-83.

Langelaar, R.J. 2019. Historical social organisation on the Eastern Tibetan Plateau: the territorial origins and etymology of tsho-ba. Inner Asia 21(1): 7-37.

Leach, E.R. 1961. Pul Eliya, a Village in Ceylon; A study of land tenure and kinship. Cambridge: Cambridge University Press.

Lévi-Strauss, C. 1982. The Way of the Masks (trans. S. Modelski). Seattle (WA): University of Washington Press.

Levine, N.E. 1981. The theory of rü kinship, descent and status in a Tibetan society, in C. Fürer-Haimendorf (ed.), Asian Highland Societies in Anthropological Perspective: 52-78. New Delhi: Sterling.

Levine, N.E. 1988. The Dynamics of Polyandry: Kinship, domesticity, and population on the Tibetan border. Chicago (IL): University of Chicago Press.

Mills, M.A. 200o. Vajra brother, vajra sister: renunciation, individualism and the household in Tibetan Buddhist monasticism. Journal of the Royal Anthropological Institute 6(1): $17-34$.

Obeyesekere, G. 1967. Land Tenure in Village Ceylon: A sociological and historical study. Cambridge: Cambridge University Press.

Peters, B.G. 2007. Steering, in M. Bevir (ed.), Encyclopedia of Governance: 930-49. Thousand Oaks (CA): Sage.

Ramble, C., P. Schweiger \& A. Travers (eds). 2013. Tibetans Who Escaped the Historian's Net: Studies in the social history of Tibetan-speaking societies. Kathmandu:Vajra Books.

Roche, G. 2016. The Tibetanization of Henan's Mongols: ethnicity and assimilation on the Sino-Tibetan frontier. Asian Ethnicity 17(1): 128-49.

Roche, G. \& H. Suzuki. 2018. Tibet's minority languages: diversity and endangerment. Modern Asian Studies 54(4): 1227-78.

Róna-Tas, A. 1955. Social terms in the list of grants of the Tibetan Tun-Huang Chronicle. Acta Orientalia Academiae Scientiarum Hungaricae 5: 249-70.

Sahlins, M. 2013. What Kinship Is - And Is Not. Chicago (IL): University of Chicago Press. Schneider, D. 1984. A Critique of the Study of Kinship. Ann Arbor (MI): University of Michigan Press.

Srinivas, S. 1994. Kindred and political patriliny: two styles in extra-local integration in Nubra Valley, Ladakh. Sociological Bulletin 43(2): 193-213. 
Stein, R. [1962] 1972. Tibetan Civilization (trans. J.E. Stapleton Driver). Stanford (CA): Stanford University Press.

Swank, H. 2014. Rewriting Shangri-La: Tibetan youth, migrations and literacies in McLeod Ganj, India. Leiden: Brill.

Wellens, K. 2011. Religious Revival in the Tibetan Borderlands: The Premi of southwest China. Seattle (WA): Washington University Press.

White, T. \& N. Fijn. 2020. Multispecies co-existence in Inner Asia. Introduction: Resituating Domestication in Inner Asia. Inner Asia 22(2): 162-82.

Yan, Yunxiang. 2003. Private Life Under Socialism: Love, intimacy, and family change in a Chinese village, 1949-1999. Stanford (CA): Stanford University Press.

Yeh, E.T. 2013: Taming Tibet. Landscape transformation and the gift of Chinese development. Ithaca/London: Cornell University Press. 